\title{
Secreted cellular prion protein binds doxorubicin and correlates with anthracycline resistance in breast cancer
}

\author{
Adrian P. Wiegmans, ${ }^{1}$ Jodi M. Saunus, ${ }^{2}$ Sunyoung Ham, ${ }^{1}$ Richard Lobb, ${ }^{1}$ Jamie R. Kutasovic, ${ }^{2}$ \\ Andrew J. Dalley, ${ }^{2}$ Mariska Miranda, ${ }^{3}$ Caroline Atkinson, ${ }^{4}$ Simote T. Foliaki, ${ }^{5}$ Kaltin Ferguson, ${ }^{2}$ \\ Colleen Niland, ${ }^{2}$ Cameron N. Johnstone, ${ }^{6}$ Victoria Lewis, ${ }^{5}$ Steven J. Collins, ${ }^{5}$ Sunil R. Lakhani, ${ }^{2,7}$ \\ Fares AI-Ejeh, ${ }^{3}$ and Andreas Möller ${ }^{1}$ \\ 'Tumor Microenvironment Laboratory, QIMR Berghofer Medical Research Institute, Herston, Queensland, Australia. \\ ${ }^{2}$ Centre for Clinical Research, Faculty of Medicine, The University of Queensland, Herston, Queensland, Australia. \\ ${ }^{3}$ Personalized Medicine Laboratory, QIMR Berghofer Medical Research Institute, Herston, Queensland, Australia. \\ ${ }^{4}$ Children's Cancer Institute Australia, Lowy Cancer Research Centre, University of New South Wales, Sydney, New \\ South Wales, Australia. ${ }^{5}$ Department of Medicine (Royal Melbourne Hospital), The University of Melbourne, Parkville, \\ Victoria, Australia. ${ }^{6}$ Cancer and Inflammation Laboratory, Olivia Newton-John Cancer Research Institute, Heidelberg, \\ Victoria, Australia. ${ }^{7}$ Pathology Queensland, The Royal Brisbane and Women's Hospital, Herston, Queensland, Australia.
}

Anthracyclines are among the most effective chemotherapeutics ever developed, but they produce grueling side effects and serious adverse events, and resistance often develops over time. We found that these compounds can be sequestered by secreted cellular prion protein ( $P r P c)$, which blocks their cytotoxic activity. This effect was dose dependent using either cell line-conditioned medium or human serum as a source of $\mathrm{PrP}^{\mathrm{c}}$. Cenetic depletion of $\mathrm{PrP}^{\mathrm{C}}$ or inhibition of binding via chelation of ionic copper prevented the interaction and restored cytotoxic activity. This was more pronounced for doxorubicin than its epimer, epirubicin. Investigating the relevance to breast cancer management, we found that the levels of PRNP transcript in pretreatment tumor biopsies stratified relapse-free survival after neoadjuvant treatment with anthracyclines, particularly among doxorubicin-treated patients with residual disease at surgery. These data suggest that local sequestration could mediate treatment resistance. Consistent with this, tumor cell expression of $\mathrm{PrP}^{\complement}$ protein correlated with poorer response to doxorubicin but not epirubicin in an independent cohort analyzed by IHC, particularly soluble isoforms released into the extracellular environment by shedding. These findings have important potential clinical implications for frontline regimen decision making. We suggest there is warranted utility for prognostic $\operatorname{PrP} / P R N P$ assays to guide chemosensitization strategies that exploit an understanding of $\mathrm{PrP}^{\mathrm{C}}$-anthracycline-copper ion complexes.

Conflict of interest: The authors have declared that no conflict of interest exists.

Copyright: (c) 2019 American Society for Clinical Investigation

Submitted: August 9, 2018 Accepted: February 13, 2019 Published: March 21, 2019.

Reference information: JCI Insight. 2019;4(6):e124092. https://doi. org/10.1172/jici.nsight.124092

\section{Introduction}

The anthracycline compounds doxorubicin (Adriamycin, Rubex) and epirubicin, a doxorubicin epimer (Ellence) are among the most important drugs in oncology. Anthracyclines are used widely for managing intermediate-to-high-risk breast cancer patients and are mainstays of treatment for triple-negative breast cancer (TNBC) (1). By directly intercalating into DNA, they block replication and induce DNA damage and apoptosis. Doxorubicin and epirubicin have different side effect profiles but similar efficacy overall, and oncologists' preference of prescribed agent is often related to prior use or hospital guidelines (2). Anthracyclines are often administered in combination with 5-fluorouracil and cyclophosphamide in the neoadjuvant setting. Initial responses to these regimens can be impressive, particularly in TNBC. However, they produce serious side effects, and, in time, up to $78 \%$ of TNBC patients experience distant relapse (3), indicating a high prevalence of intrinsic and/or acquired resistance. Nevertheless, there are few, if any, agents with demonstrated superiority (1). Key research priorities are to rationalize their use with biomarkers that reliably predict response and development of strategies to improve the side effect profile and to counteract resistance. 
Cellular prion protein $\left(\mathrm{PrP}^{\mathrm{C}}\right)$ is a small glycoprotein that is anchored to the cell membrane outer leaflet via a glycosylphosphatidylinositol (GPI) tail (4). $\operatorname{PrP}^{C}$ comprises a structured globular $\alpha$-helical $\mathrm{C}$-terminal domain and a less structured octarepeat-containing $\mathrm{N}$-terminus and is regulated by proteolytic processing at 3 sites $(\alpha, \beta$, and $\gamma)(4)$. $\operatorname{PrP}^{\mathrm{C}}$ can be secreted into the extracellular environment through GPI anchor cleavage and/or modified glycosylation (4). By acting as a multivalent scaffold protein, it has been implicated in a variety of normal biological processes that buffer cells from internal and environmental stresses (5), though its precise molecular functions are still incompletely defined. In breast cancer, expression is highest in tumors with a basal-like phenotype. $\operatorname{PrP}^{\mathrm{C}}$ has been implicated in resistance to anthracycline-based chemotherapy, though the mechanism and clinical relevance are not understood (5-7).

With a view to reconciling and determining the relevance of these observations in oncology, we conducted a comprehensive mechanistic investigation of $\mathrm{PrP}^{\mathrm{C}}$-associated chemoresistance. Through a series of hypothesis-driven in vitro studies informed by biochemical data from prion cell biology, we found that secreted $\mathrm{PrP}^{\mathrm{C}}$ specifically retards the activity of doxorubicin, preventing it from entering the nucleus and intercalating into DNA. Analyzing tumor and serum samples from breast cancer patients treated with doxorubicin-based chemotherapy suggested this could occur locally in the tumor microenvironment by reducing chemosensitivity, and/or systemically in body fluids, by reducing the bioavailability of this widely used cytotoxic agent.

\section{Results}

Characterization of prion protein expression in breast cancer and cell lines. To inform our selection of breast cancer cell lines for mechanistic experiments, we compared expression of $P R N P$ (gene coding for $\operatorname{PrP}^{\mathrm{C}}$ protein) mRNA in cell lines and human breast cancer samples, using publicly available data sets (8). Consistent with previous findings in breast tumor samples, triple-negative (TN) and basal-like breast cancer subtypes expressed the highest PRNP mRNA levels (Figure 1A and Supplemental Figure 1A). Within these groups, the highest $P R N P$ expression was associated with claudin-low and mesenchymal signatures characteristic of mesenchymal-like TNBCs (Figure 1A). It has been suggested that tissue homogenates from mesenchymal-like TNBCs are enriched with stromal cells, but there was only a weak correlation between tumor purity and PRNP in TNBCs ( $r=0.19$; Supplemental Figure 1B), suggesting that the values largely reflect cancer cell expression. Indeed, $P R N P$ expression was also high in claudin-low/basal-B compared with luminal-like cell lines (Supplemental Figure 1, C-F). There was no association between gene copy number and mRNA expression in TCGA data sets (Figure 1B), but expression was weakly and inversely correlated with methylation of the PRNP genomic locus in TN cancer sample subtypes (Figure 1C) and cell lines (Supplemental Figure 1G), suggesting that epigenetic programming is a determinant of expression to some degree. In cell lines in which $\mathrm{PrP}^{\mathrm{C}}$ was readily detectable, protein expression was moderately consistent with mRNA expression $(r=0.6)$; however, there were multiple PRNP-positive cell lines with undetectable intracellular $\operatorname{PrP}^{\mathrm{C}}$ protein, suggesting that posttranscriptional/translational mechanisms also regulate $\operatorname{PrP}^{\mathrm{C}}$ (Supplemental Figure 1, E and F).

In contrast to the cell line data presented above, there was a strong inverse relationship between PRNP mRNA and $\mathrm{PrP}^{\mathrm{C}}$ protein expression in lysates from a unique set of MDA-MB-231 (MDA231) clonal derivatives when arranged according to metastatic potential (Figure 1D) (9). Hypothesizing that this discrepancy could be due to secretion of the protein via exosomes (10), we assayed $\operatorname{PrP}^{\mathrm{C}}$ in exosome preparations from the highly metastatic HM.LNm5 clone. Interestingly, we found no exosome-associated $\mathrm{PrP}^{\mathrm{C}}$ protein, suggesting that it is secreted independently (Figure 1E). Consistent with this, there was a dose-dependent increase in intracellular $\mathrm{PrP}^{\mathrm{C}}$ following treatment of HM.LNm5 with a ER-Golgi decoupling agent, brefeldin A (Figure 1F). $\mathrm{PrP}^{\mathrm{C}}$ levels in whole cell lysates from other TN mesenchymal lines also increased after brefeldin A treatment (Figure 1G). This difference was most noticeable and statistically significant in MDA231 and BT549 cells (Figure 1G), which also secreted the most $\mathrm{PrP}^{\mathrm{C}}$ into culture medium (Figure $1 \mathrm{H}$ ) and exhibited the most obvious colocalization of $\operatorname{PrP}^{\mathrm{C}}$ with the Golgi marker GM130 (Figure 1I).

Collectively, these data contextualize the regulation of $\mathrm{PrP}^{\mathrm{C}}$ in breast cancer and suggest that high expression is associated with exosome-independent secretion of the protein into the extracellular environment.

Extracellular $\operatorname{Pr} P^{C}$ can mediate resistance to doxorubicin. Next, we investigated the relationship between $\operatorname{PrP}^{\mathrm{C}}$ secretion and sensitivity to various breast cancer chemotherapeutics, including doxorubicin (anthracycline), cisplatin (alkylating agent), docetaxel (taxane), gemcitabine (antimetabolite), and gefitinib (EGFR inhibitor). In vitro dose-response experiments were performed comparing $\mathrm{IC}_{50}(50 \%$ of the 
A

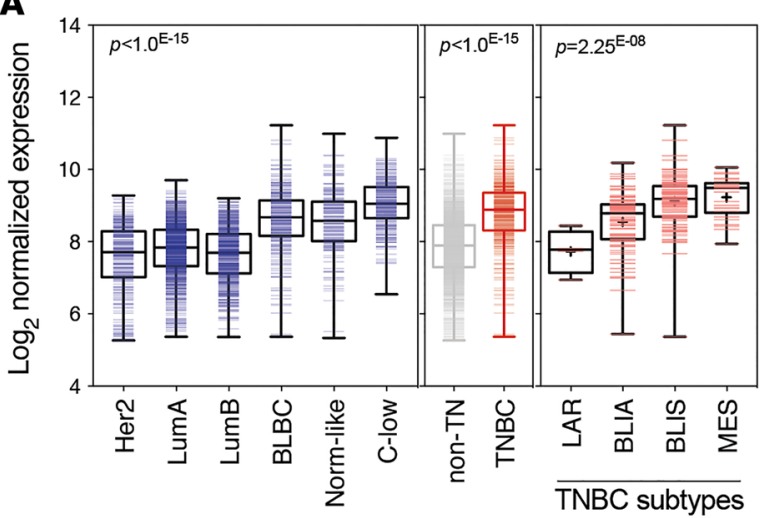

B
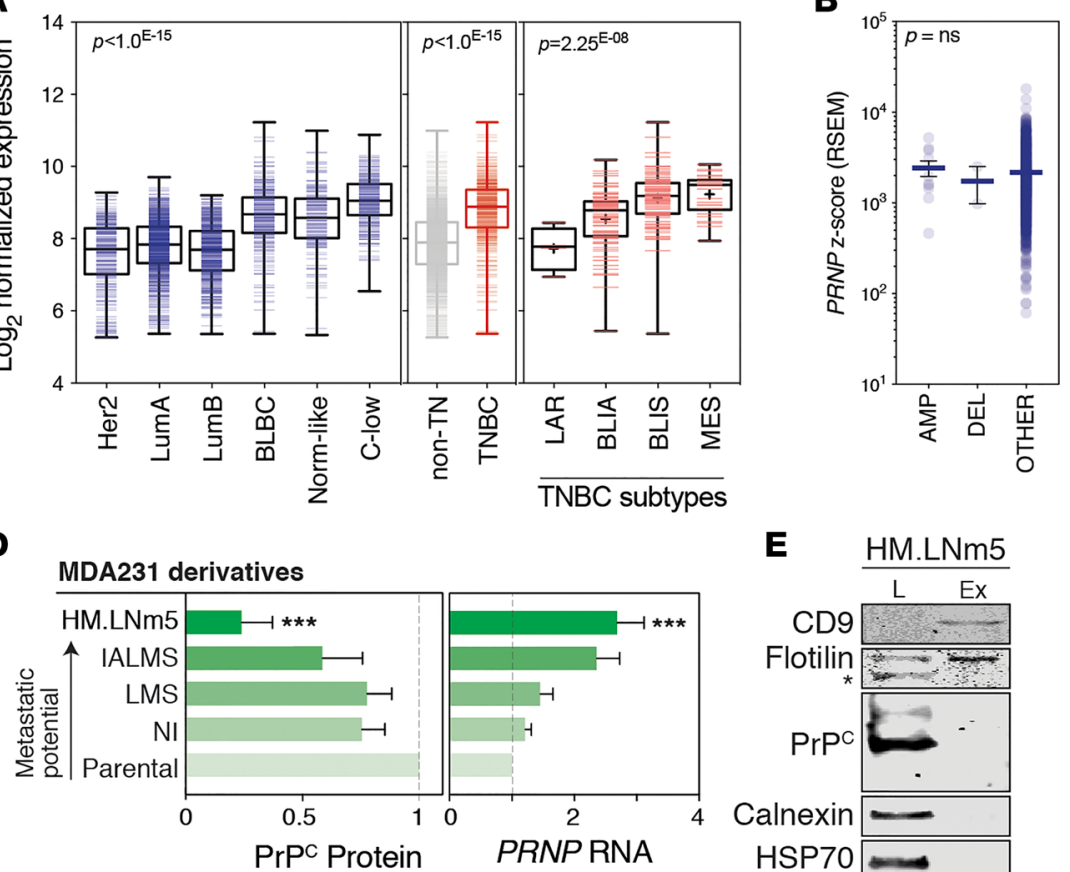

E HM.LNm5

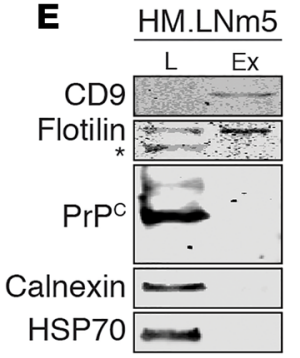

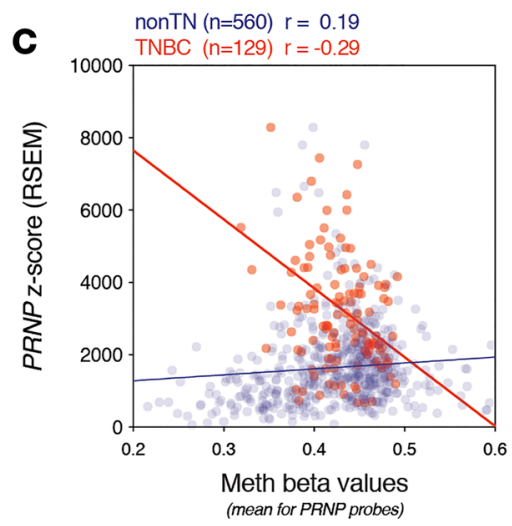

$\mathbf{F}$

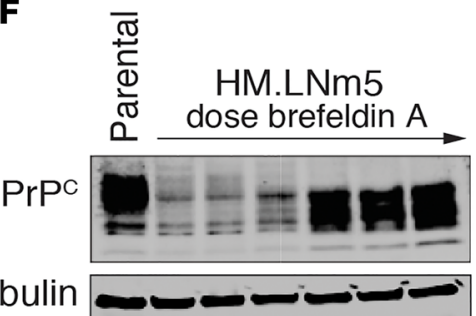

G

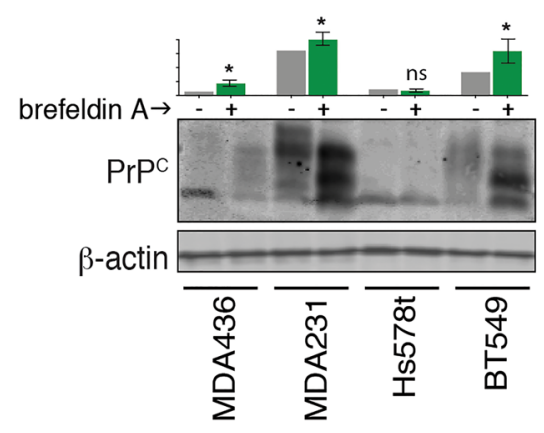

H

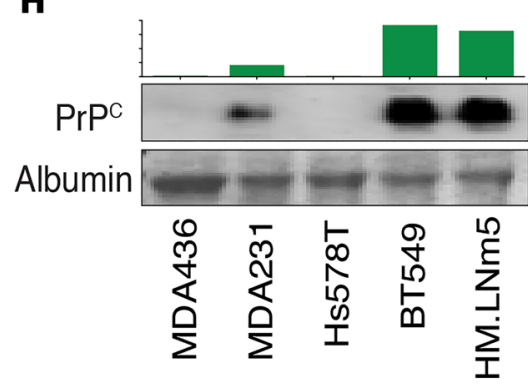

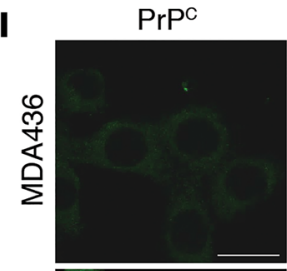
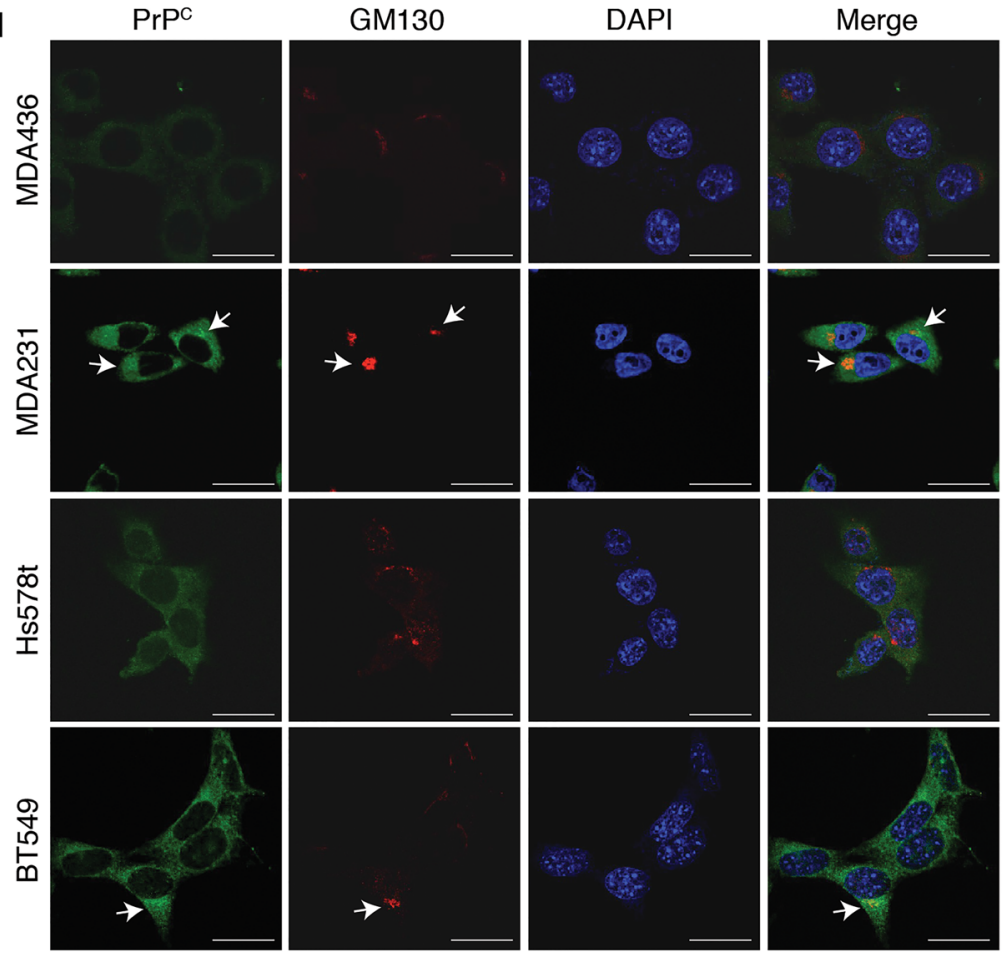

Figure 1. PrPc expression in breast tumors and cell lines. (A) Analysis of PRNP mRNA expression in the Metabric data set. PRNP is more highly expressed in basal-like (BLBC), claudin-low (C-low), and normal-like (Nom-like) breast cancers compared with Her2-enriched (Her2) or luminal A/B types (LumA, LumB). Expression is highest in triple-negative breast cancers (TNBC), with basal-like immune-suppressed (BLIS) and mesenchymal phenotypes (MES), and lower in luminal androgen receptor (LAR) and basal-like immune-activated (BLIA). Boxes represent median \pm interquartile range; whiskers represent minutes/max values; + symbols represents the mean for each group. $P$ values were determined using nonparametric analysis of variance (Kruskal-Wallis test). (B) Frequency of copy number alterations at the PRNP locus and relationship with mRNA expression in the TCGA data set (amp, amplification; del, deletion). $P$ values were determined using nonparametric analysis of variance (Kruskal-Wallis test). (C) Relationships between PRNP gene methylation and mRNA expression in TNBCs from the TCGA data set. $r$, correlation coefficients. (D) Expression of PrPc protein and mRNA in a series of MDA231 clonal derivatives with increasing metastatic potential. Protein was quantified relative to $\beta$-actin by densitometry and expression levels compared with the parental cell line $\left(n=3 ;{ }^{* *} P=0.002\right.$; see Supplemental Figure $\left.1 \mathrm{H}\right)$. RNA was quantified relative to $\beta$-actin by qRT-PCR $\left(n=5 ;{ }^{* *} P=0.003\right)$. (E) Western analysis of PrPc, exosome markers (CD9, flotillin) and loading controls (HSP70, 
inhibitory dose) values across the same panel of cell lines. Those that secreted the most soluble $\operatorname{PrP}^{\mathrm{C}}$ (HM.LNm5, BT549, and MDA231) were the most resistant to doxorubicin (Figure 2, A and B), but there was no association between secreted $\mathrm{PrP}^{\mathrm{C}}$ levels and the other compounds tested (Supplemental Figure 2, A and B). siRNA-mediated depletion of PRNP from HM.LNm5 (PrPC-high), BT549 (PrPC_ high), and MDA231 ( $\mathrm{PrP}^{\mathrm{C}}$-high) cells sensitized them to doxorubicin proportionally to their baseline levels of $\mathrm{PrP}^{\mathrm{C}}$ secretion (135-, 130-, and 5-fold, respectively; Figure 2C and Supplemental Figure 2, C and D). No change in sensitivity was observed in PRNP-depleted Hs578T cells $\left(\mathrm{PrP}^{\mathrm{C}}\right.$-low; Figure $2 \mathrm{C}$ and Supplemental Figure 2, C and D), suggesting the effect was specifically related to $\operatorname{PrP}^{\mathrm{C}}$ expression levels. Indeed, supplementing PRNP-depleted HM.LNm5 cells with conditioned media from untreated, $\mathrm{PrP}^{\mathrm{C}}$-containing HM.LNm5 cultures partially restored doxorubicin resistance irrespective of whether media were first depleted of exosomes (Figure 2D). The partial response is likely due to reduced $\operatorname{PrP}^{\mathrm{C}}$ in SCRsi-conditioned medium compared with nontransfected conditioned medium and the multiple changes of media required in the procedure (Supplemental Figure 2E).

Proteolytic cleavage of $\mathrm{PrP}^{\mathrm{C}}$ at 3 different sites is known to regulate subcellular distribution and secretion. These sites are at residue 111 ( $\alpha$-cleavage), at residue 90 near the end of the octapeptide repeat region ( $\beta$-cleavage), and at or near the GPI anchor (shedding) (4). Depending on the specific processing, cleavage can occur during or after transport to the plasma membrane. The process is regulated by various though incompletely defined proteases and also the local abundance of divalent cations, such as zinc and copper, which physically bind the octarepeat region of $\operatorname{PrP}^{\mathrm{C}}$ (11). To determine which isoforms were secreted by the doxorubicin-resistant cell lines, we used isoform-specific antibodies to profile $\mathrm{PrP}^{\mathrm{C}}$ in cell lysates and conditioned media: full-length deglycosylated $\mathrm{PrP}^{\mathrm{C}}$ ( $\mathrm{FL}^{27}$; $\mathrm{PNG}$ aseF treated), full-length glycosylated $\mathrm{PrP}^{\mathrm{C}}$ $\left(\mathrm{FL}^{37}\right)$, and cleavage products. This included the 3F4 antibody, which discriminates $\mathrm{C}$-terminal products of $\alpha$ - and $\beta$-cleavage, and SAF32, which binds the octarepeat region (Figure 2E). These experiments showed that an increase in soluble, full-length $\mathrm{PrP}^{\mathrm{C}} \mathrm{FL}^{27}$ correlated with doxorubicin resistance, supporting the idea that shedding is related to therapeutic resistance. Indeed, $\mathrm{FL}^{27}$ was readily detectable in conditioned media from the highly secretory, resistant lines BT549 and HM.LNm5 (Figure 2E). These data show that in an in vitro setting, processed, soluble $\mathrm{PrP}^{\mathrm{C}}$ can mediate resistance to doxorubicin (Figure $2 \mathrm{~F}$ ).

Extracellular $\operatorname{Pr} P^{C}$ in human serum can sequester doxorubicin. In light of reports that doxorubicin can neutralize $\operatorname{PrP}^{\mathrm{Sc}}$ isoforms in the brain (12), we hypothesized that $\operatorname{PrP}^{\mathrm{C}}$ might reduce doxorubicin bioavailability through sequestration. $\mathrm{PrP}^{\mathrm{C}}$ has been detected in blood (13), so we tested whether serum from breast cancer patients could recapitulate the effect of conditioned culture medium, using HM.LNm5 cells depleted of endogenous $P R N P$ as a reporter of doxorubicin sensitivity. The $\mathrm{IC}_{50}$ for doxorubicin in PRNP-depleted HM.LNm5 cells $(0.009 \mu \mathrm{M})$ is within the range of doxorubicin concentrations measured in the blood of breast cancer patients (Cmax -0.276 at $75 \mathrm{mg} / \mathrm{m}^{2}$ dose $0.01-0.1 \mu \mathrm{M}$; ref. 14). We substituted fetal calf serum with breast cancer patient serum with known $\mathrm{PrP}^{\mathrm{C}}$ concentrations and measured the effect on cell viability over a range of doxorubicin doses (Figure 3A). Both samples tested restored doxorubicin resistance in $\mathrm{PrP}^{\mathrm{C}}$-depleted cells (Figure $3 \mathrm{~A}$ ). Clearing soluble $\operatorname{PrP}^{\mathrm{C}}$ from the serum by immunoprecipitation before treatment impeded this (Figure 3B), and, accordingly, levels of intercalated doxorubicin in nuclei were reduced in cells treated with human serum (Figure 3, C and D). Of note, high concentrations of doxorubicin were observed outside the nucleus, most likely associated with $\operatorname{PrP}^{\mathrm{C}}$ accumulation in the Golgi apparatus (Figure 3C).

To investigate the potential clinical implications, we performed high-throughput screening of a larger set of patient serum samples. We tested the ability of each sample to restore resistance of $P R N P$-depleted HM.LNm5 cells to doxorubicin or epirubicin and compared this to the $\operatorname{PrP}^{\mathrm{C}}$ concentration in each sample. Serum $\mathrm{PrP}^{\mathrm{C}}$ was quantified by ELISA using the $3 \mathrm{~F} 4$ antibody, which preferentially binds processed full-length and C2 isoforms (Figure 2E). For both drugs, there was a correlation between resistance and serum $\operatorname{PrP}^{\mathrm{C}}$ concentration; however, only doxorubicin reached significance and had a higher correlation coefficient ( $r^{2}=0.71$ vs. 0.15 for epirubicin; Figure 3E). Similar trends were found in PRNP-depleted BT549 cells (Figure 3F). Consistent with this, PRNP siRNA did not sensitize HM.LNm5 cells to epirubicin (Supplemental Figure 3B compared with Figure 2C), and doxorubicin could be coimmunoprecipitated with $\mathrm{PrP}^{\mathrm{C}}$ from conditioned media of treated HM.LNm5 cells at significantly higher levels than epirubicin using 2 different antibodies (Figure 3G and Supplemental Figure 3A). Therefore, despite differing only by epimerization of the aminosugar hydroxyl group (Figure $3 \mathrm{H}$ ), doxorubicin and epirubicin have distinctly different affinities for $\mathrm{PrP}^{\mathrm{C}}$ in an in vitro environment. 


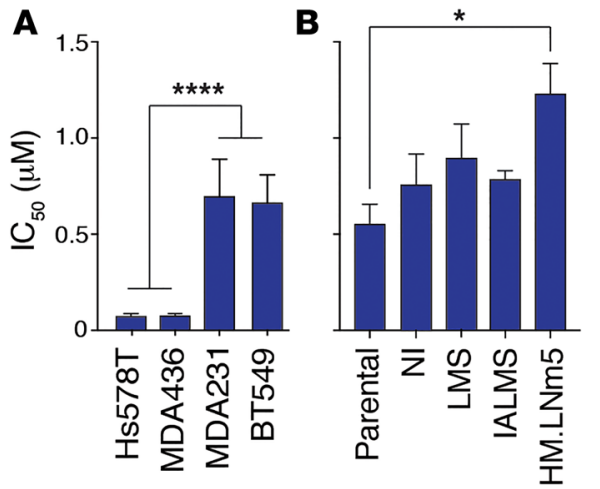

D $\begin{aligned} \text { SiRNA } & \text { media } \\ \sim \text { SCRsi } & \text { regular } \\ \sim \text { SRNPsi } & \text { SCRsi-CM } \\ - \text { - PRNPsi } & \text { PRNPsi-CM }\end{aligned}$

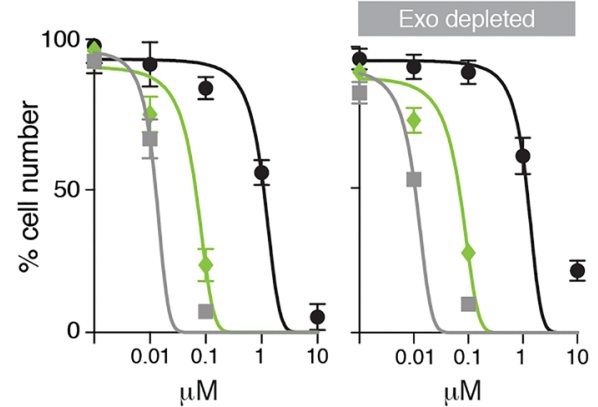

$\mathbf{F}$
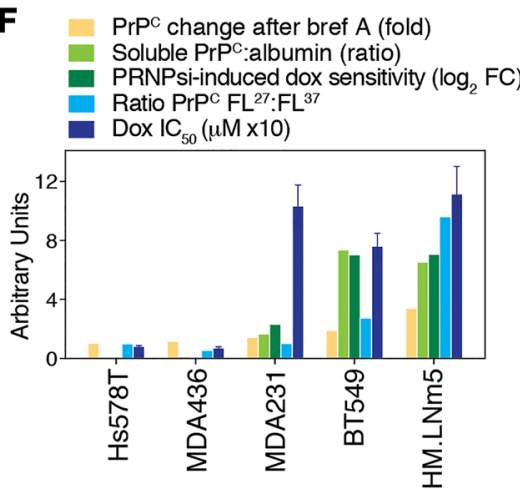

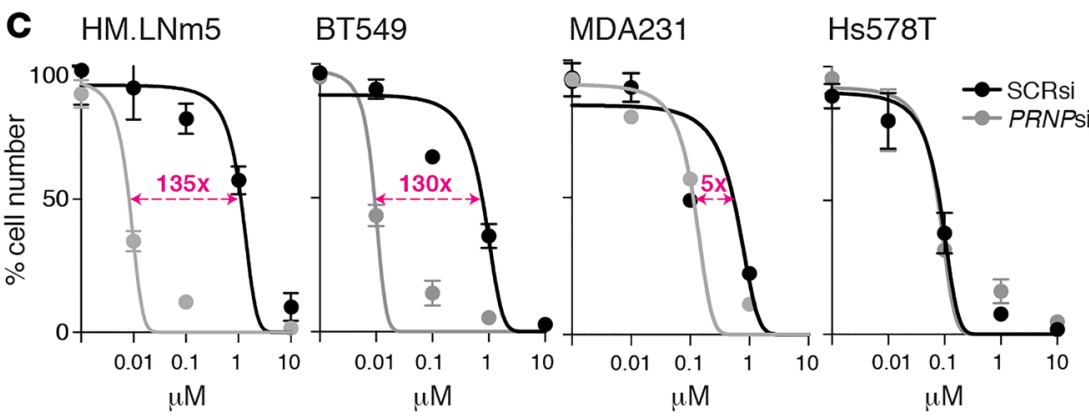

$\mathbf{E}$
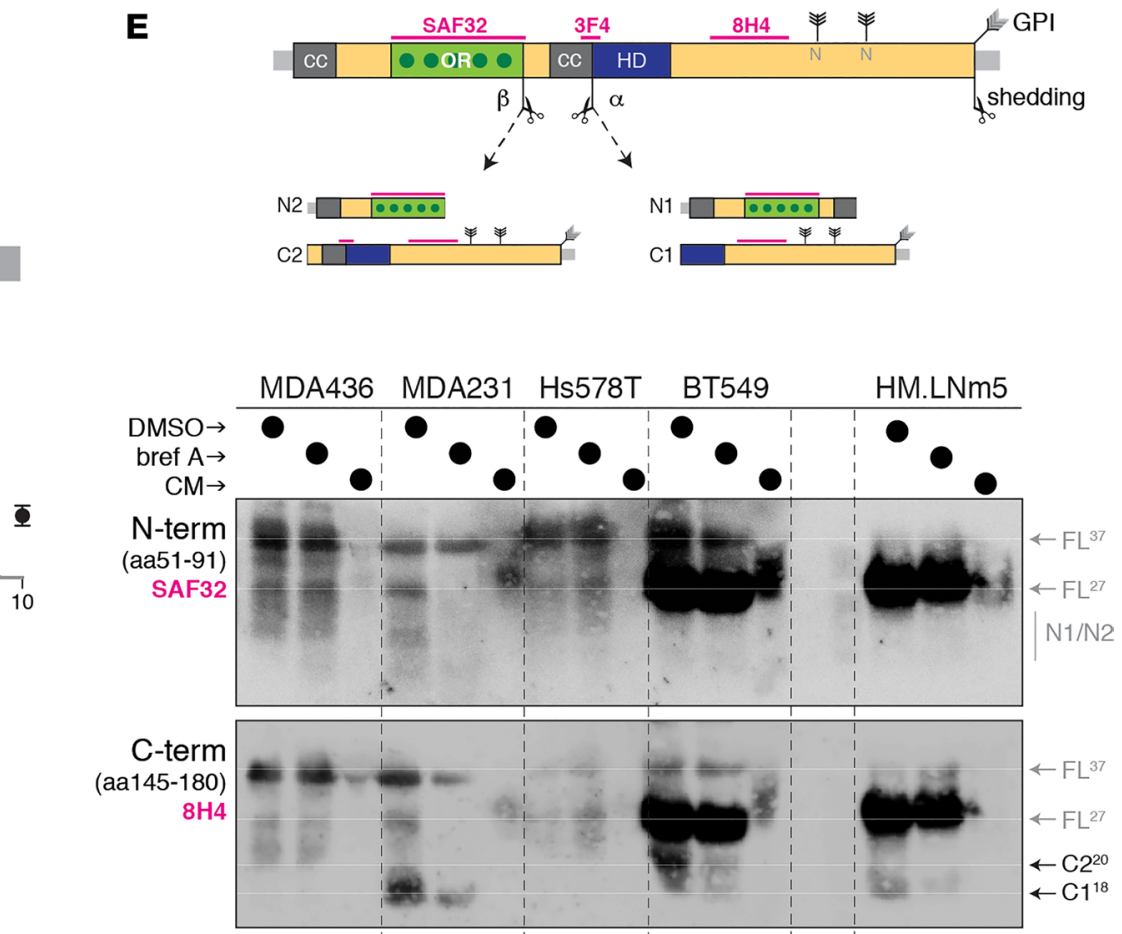

$\alpha$-cleavage site (aa106-112) $3 \mathrm{~F} 4$

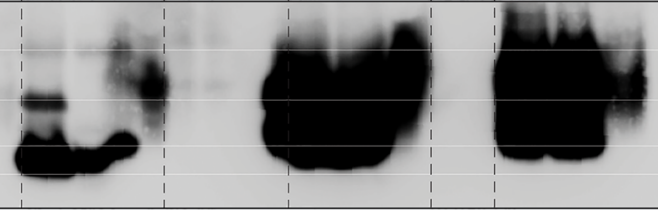

Figure 2. Soluble PrPc can mediate resistance to doxorubicin. (A and B) Baseline doxorubicin $\mathrm{IC}_{50}$ values (mean \pm SEM from 3 independent experiments) comparing cell lines secreting different levels of $\operatorname{PrPC}\left({ }^{* * *} P=0.001\right.$, comparing Hs578t/MDA436 versus MDA231/BT549; ${ }^{*} P=0.05$, comparing HM.LNm5 and parental; see Supplemental Figure 2). $P$ values were determined using 2-tailed Student's $t$ test. (C) Doxorubicin dose curves in various cell lines after depleting PrPC with siRNA (confirmation of knockdown shown in Supplemental Figure 2, C and D). SCRsi, scrambled siRNA control sequence. (D) Doxorubicin dose curves for MDA231 and HM.LNm5 cells depleted of PrPC and then supplemented with media from parallel cultures of PRNPsi or SCRsi transfectants. The experiment was also performed using equivalent media depleted of exosomes. (E) Western analysis of PrP ${ }^{\complement}$ fragments present in lysates from 5 cell lines treated with DMSO (control) or brefeldin A, compared with conditioned medium (CM) from untreated cells. Cleavage at the $\alpha$ site produces N1 and C1 fragments, while $\beta$-cleavage produces N2 and C2. Shedding of full-length or C1/2 fragments occurs by proteolytic cleavage at or near the glycosylphosphatidylinositol (GPI) membrane anchor. Blots were probed with the 3 different antibodies, the epitopes for which are indicated on the PrPc schematic (drawn to scale). Protein preparations were first treated with the amidase peptide- $\mathrm{N}$-glycosidase (PNGase-F) to resolve glycoprotein fragments at their respective molecular masses in denaturing conditions. CC, charged cluster domain; OR, octarepeat domain with dark-green dots as high-affinity copper-binding histidine residues; HD, hydrophobic domain; FL37, full-length glycosylated protein; FL27, full-length deglycosylated protein. N-linked glycosylation sites are also shown. (F) Summary plot of fold change across various units, demonstrating the positive association among cell lines in terms of intracellular accumulation of PrPC protein levels after brefeldin A treatment (yellow; from Figure 1, $\mathrm{G}$ and $\mathrm{H}$ ), levels of PrPc protein secretion into conditioned media (light green; Figure 1I), dependence on PRNP expression for doxorubicin resistance expressed in units as doubling fold change (dark green; $\mathbf{C}$ ), ratio of free to membrane-bound full-length PrPC (light blue; E), and the baseline doxorubicin $\mathrm{IC}_{50}$ (dark blue; Supplemental Figure 2, A and B). BT549 and HM.LNm5 were identified as the best models of soluble PrPc-associated doxorubicin resistance. 
A siRNA serum $\operatorname{PrP}^{\mathrm{C}}(\mathrm{ng} / \mathrm{mL})$ - SCRsi FBS - PRNPsi FBS

는- PRNPsi B1288 47.3

- PRNPsi B474 110.3

$\square$ Usual plasma dox range
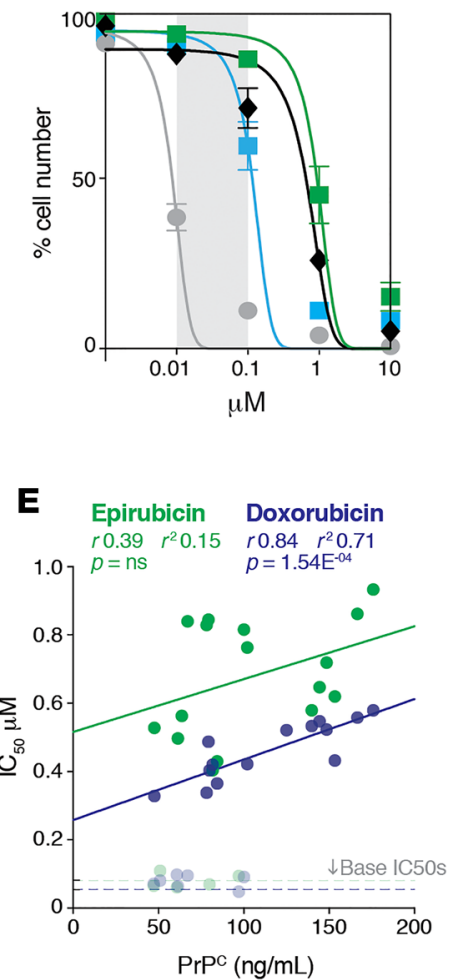

B
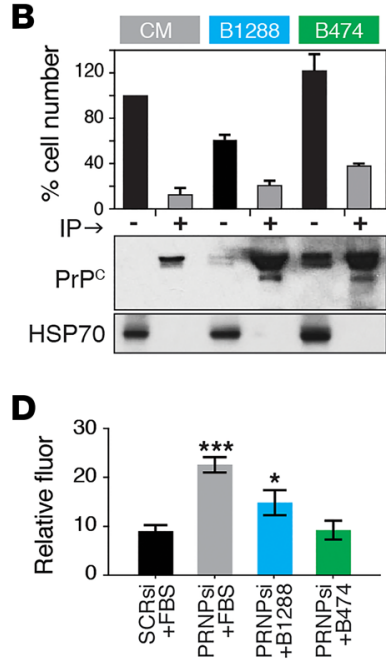

$\mathbf{F}$

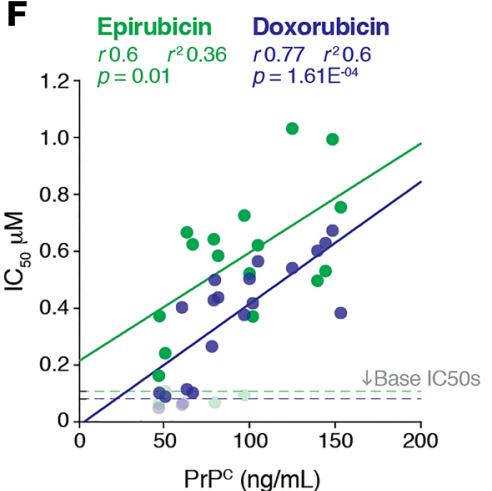

c

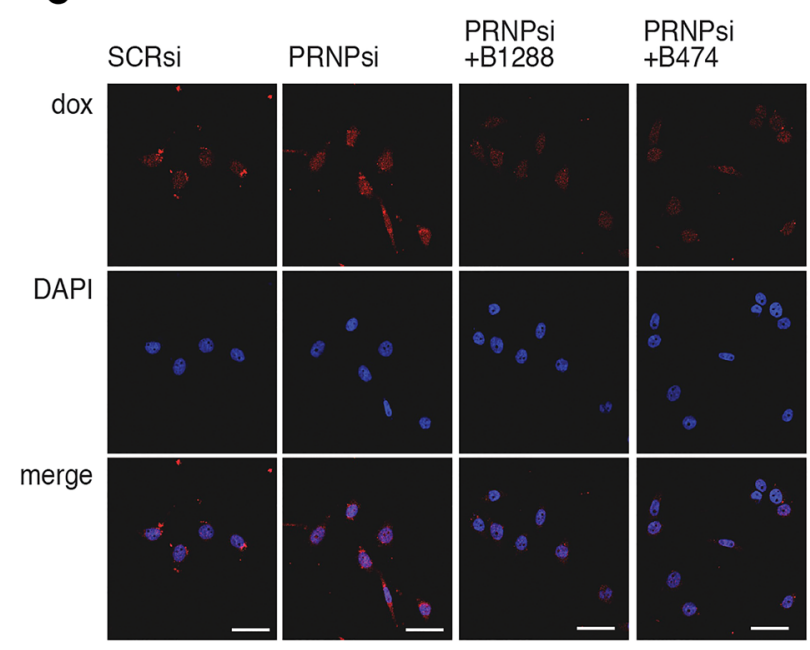

G

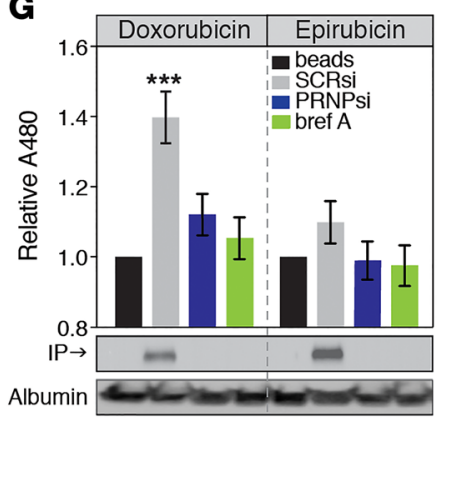

H
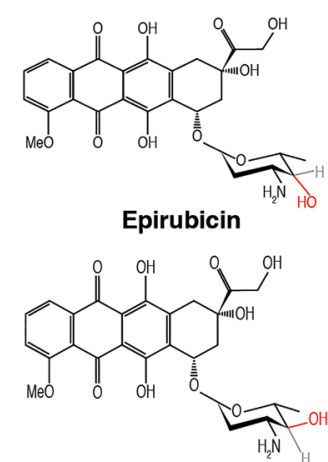

Figure 3. Effect of PrPC-positive serum and tumor tissue on doxorubicin efficacy. (A) Comparison of doxorubicin dose-response profiles in HM.LNm5 cells supplemented with $10 \%$ FBS or 10\% serum from patients B1288 or B474. For patient serum assays, cells were first depleted of endogenous PRNP using siRNA. Serum $\operatorname{PrP}^{\mathrm{C}}$ concentration was measured by ELISA. The assay was performed within a physiologically relevant range of doxorubicin concentrations (gray shading, 10-100 nM, 24-96 hours after infusion of $75 \mathrm{mg} / \mathrm{m}^{2}$ dose; ref. 14). (B) PRNP-depleted HM.LNm5 cells were incubated for 72 hours with conditioned medium from SCRsi-transfected HM.LNm5 (CM) cells or media from PRNP-depleted HM.LNm5 cells supplemented with $10 \%$ human serum. Parallel cultures were incubated after specific depletion of PrPc by immunoprecipitation (IP; 3F4 antibody). Western shows PrPC levels (with 1\% of input blotted for HSP70 as a loading control), and the bar graph shows the effect of depleting PrPc from the media on total cell number after 72 hours growth in the presence of doxorubicin $(1 \mu \mathrm{M}$; mean \pm SEM from 3 assays). (C and $\mathbf{D})$ Fluorescent imaging of doxorubicin (red) in the nuclei of $P R N P$-depleted HM.LNm5 cells cultured with human serum. Ten image fields were analyzed in triplicate (PRNPsi, $\left.{ }^{* * *} P=0.002 ;+B 1288,{ }^{*} P=0.045\right)$. Scale bar: $100 \mathrm{~nm}$. (E) Correlation between patient serum PrPC concentration (determined by ELISA) and doxorubicin or epirubicin IC in $_{50}$ inNP-depleted HM.LNm5

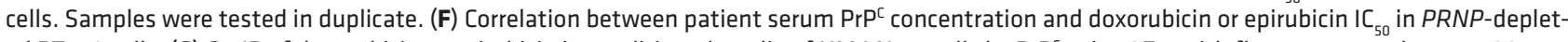
ed BT549 cells. (G) Co-IP of doxorubicin or epirubicin in conditioned media of HM.LNm5 cells by PrPC using 3F4, with fluorescent readout at $480 \mathrm{~nm}$ compared with control IP of beads alone. Conditioned media albumin was a loading control (mean $\pm \mathrm{SEM}$ is shown for 3 experiments; $\left.{ }^{* * *} P=0.005\right)$. (H) Comparison of doxorubicin and epirubicin structures, highlighting epimerization of the sugar moiety hydroxyl group.

Tumor-derived $\operatorname{PrP}^{C}$ is associated with poor response to anthracycline-based chemotherapy. Our biochemical and in vitro experiments suggested that if either free or membrane-bound $\operatorname{PrP}^{\mathrm{C}}$ sequestered anthracyclines in the tumor microenvironment, this could reduce bioavailability and promote drug resistance. Additionally, prior knowledge of tumor $\mathrm{PrP}^{\mathrm{C}}$ expression and/or levels of soluble, serum-derived $\mathrm{PrP}^{\mathrm{C}}$ perfusing the tumor could help to rationalize the prescription of doxorubicin- or epirubicin-based therapies in the clinic. Using published gene expression array data sets, we compared pretreatment tumor samples of neoadjuvant FAC and FEC clinical trial cohorts and stratified cases that failed to achieve a pathologic complete response (pCR) by PRNP mRNA expression. PRNP was a powerful predictor of response to therapy in these analyses, with high expression associated with relapse in both groups (Figure 4A). This was particularly evident for the FAC regimen, where high PRNP (tertile 3; $27 \%$ of the cohort overall) was associated with a hazard ratio of 4.36 (95\% CI $\left.2.43-7.82 ; P=1.54 \times 10^{-10}\right)$. In terms of study biases that could contribute to these trends, we did 


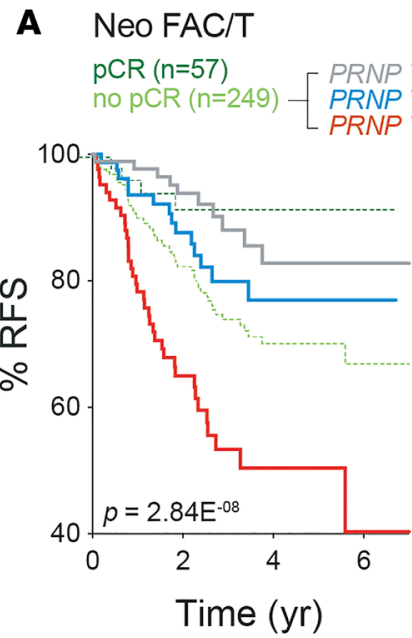

C SAF32
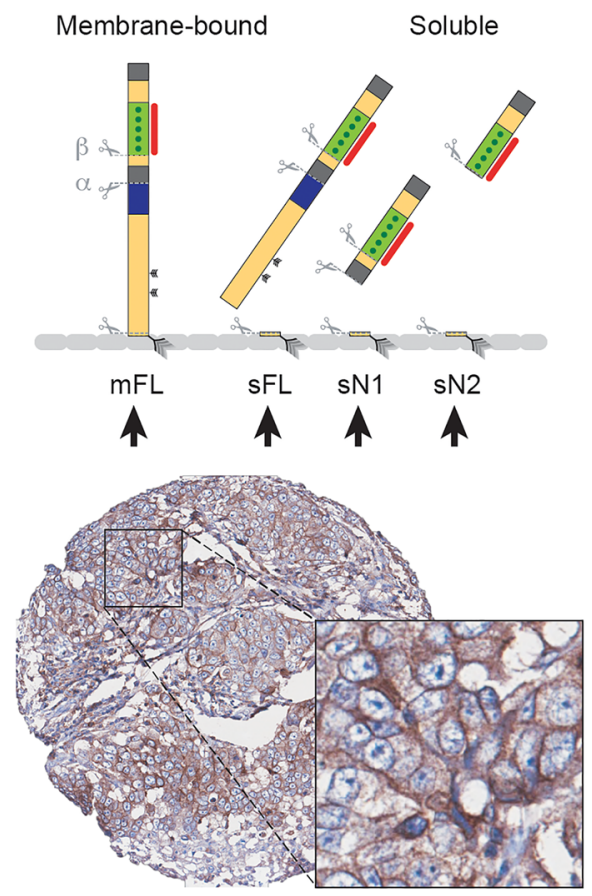

Neo FEC/T

$\mathrm{pCR}(\mathrm{n}=23)$ no pCR $(n=67)-\left[\begin{array}{l}\text { PRNP T1 } \\ \text { PRNP T2 } \\ \text { PRNP T3 }\end{array}\right.$

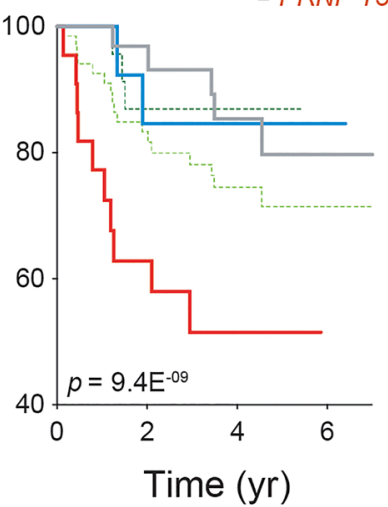

B
Adjuvant CTx (any)

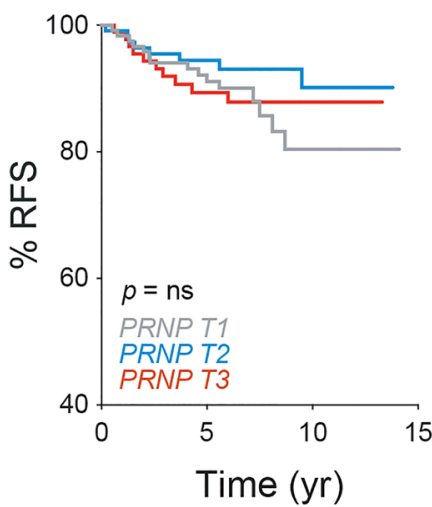

Adjuvant TAM

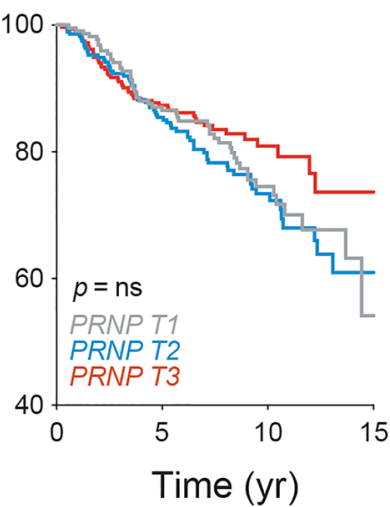

E
D $\quad 3 F 4$

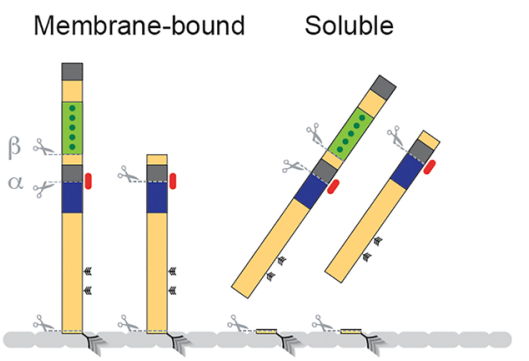

$\mathrm{mFL} \quad \mathrm{mC2}$
$\mathrm{sFL} \quad \mathrm{sC2}$

个

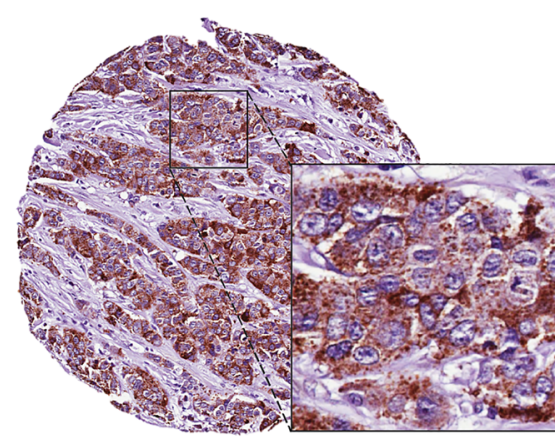

$3 F 4(-)$

3F4 (+)

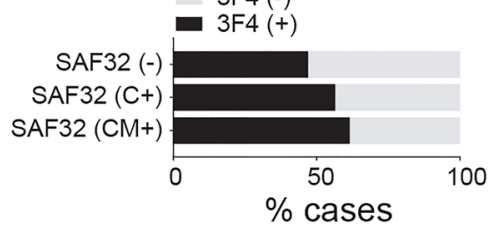

F Adjuvant FAC/FEC

[FAC] $\mathrm{PrP}_{+}$[FEC] $\mathrm{PrPC}_{+}$

[FAC] $\mathrm{PrP}_{-}$[FEC] $\mathrm{PrP}_{-}$

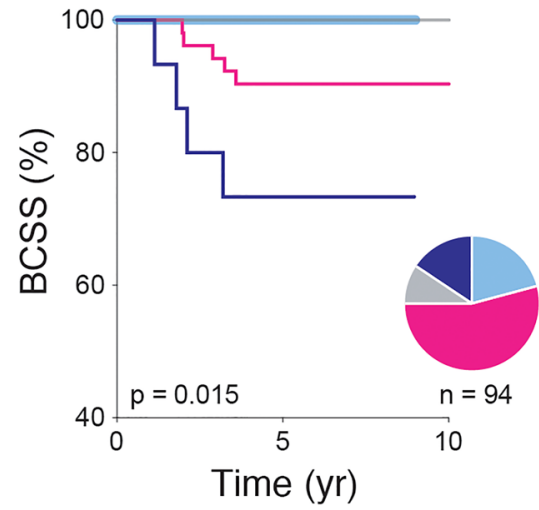

Figure 4. Relationships between tumor PrP ${ }^{\mathrm{c}}$ expression and clinical outcomes of breast cancer patients treated with anthracycline-based chemotherapy. (A) Kaplan-Meier (KM) analysis of relationships between PRNP mRNA and relapse-free survival (RFS) using neoadjuvant trial data sets from the KM plotter database. pCR, pathologic complete response; PRNP T1-3, expression tertiles; FAC/T, fluorouracil, Adriamycin (doxorubicin), cyclophosphamide + taxane regimen; $\mathrm{FEC} / \mathrm{T}$, as for FAC/T but with epirubicin instead of Adriamycin. Log-rank tests were used to quantify the statistical significance of differences. (B) No association between PRNP expression and RFS in general chemotherapy- (CTX-) or tamoxifen (TAM-treated) cohorts. Analysis also performed using KM-Plotter data sets. (C-F) Relationships between tumor cell expression of PrPC protein isoforms and breast cancer-specific survival (BCSS) in the Brisbane Breast Bank anthracycline chemotherapy cohort (Tables 1 and 2). (C and D) Membrane-bound (m) and soluble (s) PrPc isoforms potentially detectable with SAF32 and 3F4 antibodies (epitopes highlighted red) and representative immunohistochemical (IHC) detection with SAF32 and 3F4, illustrating the typical staining patterns observed: both plasma membrane and punctate cytoplasmic staining with SAF32; stronger punctate cytoplasmic staining with 3F4. Arrows indicate the observed versus theoretically detectable isoforms. 3F4 preferentially detected soluble (sheddase processed; see Figure 2 ) full-length (sFL) and/or sC2 ( $\beta$-cleavage product) isoforms in these conditions. Images are $600 \mu \mathrm{M}$ in diameter (original magnification, $\times 40$ ); insets are $110 \mu \mathrm{M}$ in diameter (zoom, $\times 135)$. (E) Weak association between SAF32 and 3F4 positivity (SAF32: -, negative; $C_{+}$, cytoplasm positive; CM+, cytoplasm and membrane positive). (F) KM analysis performed after categorizing cases according to positivity for either antibody. All breast cancer-related deaths in this cohort were characterized by positive tumor cell staining with SAF32 and/or 3F4 antibodies. Log-rank $P$ value for trend is indicated. The pie chart shows proportions of the cohort in each category (also see Tables 1 and 2). 
Table 1. Characteristics of the Brisbane Breast Bank anthracycline chemotherapy cohort

\begin{tabular}{|c|c|c|c|c|c|c|}
\hline & \multicolumn{3}{|c|}{ FAC group } & \multicolumn{3}{|c|}{ FEC group } \\
\hline & $n$ & Median & $95 \% \mathrm{Cl}$ & $n$ & Median & $95 \% \mathrm{Cl}$ \\
\hline Follow up (yr) & 24 & 5.2 & $4.15-8.28$ & 71 & 6.94 & $5.6-7.7$ \\
\hline Patient age (yr) & 24 & 46.98 & $42.59-60.65$ & 71 & 51.38 & $48.67-54.08$ \\
\hline Patient weight (kg) & 21 & 71 & $60-86$ & 63 & 76.7 & $69-81$ \\
\hline Patient height $(\mathrm{cm})$ & 20 & 160 & $156-166$ & 63 & 163 & $160-164$ \\
\hline Tumor size (mm) & 24 & 25 & $18-33$ & 68 & 30 & $25-35$ \\
\hline
\end{tabular}

not find any significant differences in proportions of breast cancer subtypes between FAC and FEC groups (data not shown), and two different $P R N P$ array probes produced similar trends (Supplemental Figure 4A). PRNP only stratified outcome in anthracycline data sets; there were no significant findings in general chemotherapy or tamoxifen cohorts (Figure 4B).

We followed up these findings with an IHC study to investigate whether similar trends were evident with $\mathrm{PrP}^{\mathrm{C}}$ protein isoforms expressed specifically by the tumor compartment of sampled tissues. Formalin-fixed, paraffin-embedded tumor tissue from an independent cohort of 95 patients treated with adjuvant FAC or FEC chemotherapy (Table 1) was sampled in duplicate into tissue microarrays (TMAs). We then performed IHC analysis on serial TMA sections using two different antibodies with overlapping isoform specificity profiles: SAF32 and 3F4. SAF32 can theoretically detect membrane-bound and soluble intracellular isoforms of $\mathrm{PrP}^{\mathrm{C}}$ (Figure 4C, top) and, indeed, produced continuous and discontinuous membrane staining, with weak-to-moderate, punctate cytoplasmic staining by IHC (Figure 4C, bottom, and Supplemental Figure 4B). Conversely, 3F4 staining was cytoplasmic and punctate (Figure 4D, bottom, and Supplemental Figure 4C), consistent with its epitope being more accessible in processed isoforms transiting through the secretory pathway. There was no obvious staining of the plasma membrane with $3 \mathrm{~F} 4$, indicating that, under these experimental conditions, its epitope is masked in full-length, membrane-bound $\mathrm{PrP}^{\mathrm{C}}$ and/or that it binds soluble isoforms generated by shedding and/or $\beta$ processing with much higher affinity (Figure $4 \mathrm{D}$, top). Consistent with having overlapping substrates, there was a weak association between SAF32 and 3F4 positivity in the cohort (Figure 4E), but both stratified survival to some degree, particularly among patients treated with FAC and particularly the 3F4 antibody, which preferentially detects soluble $\operatorname{PrP}^{\mathrm{C}}$ $(P=0.019$; Supplemental Figure 4D). Classifying cases according to whether they exhibited any positivity for either antibody produced the most accurate stratification of breast cancer-specific survival in both anthracycline-based treatment cohorts $(P=0.015$; Figure $4 \mathrm{~F})$.

Taken together with the analysis of clinical trial data sets (Figure $4 \mathrm{~A}$ ), these data indicate a consistent relationship between tumor expression of $\mathrm{PrP}^{\mathrm{C}}$ and response to anthracycline treatment.

Complexing of doxorubicin and $\operatorname{Pr} P^{C}$ requires free copper ions. Interestingly, $\operatorname{Pr}^{C}$ and anthracyclines bind transition metals in physiologic conditions, and there is evidence for biochemical complexing of both to copper $(11,15)$. The highly conserved $\operatorname{PrP}^{\mathrm{C}}$ octarepeat region contains 6 binding domains that are highly selective for copper and zinc over other divalent metals (Figure 5A). A normal physiologic function may be to buffer cells against oxidative damage from uncomplexed copper, and/or transmembrane copper transport, as copper binding changes the conformation of $\mathrm{PrP}^{\mathrm{C}}$ and stimulates endocytosis (16). Reasoning that the propensity of $\operatorname{PrP}^{\mathrm{C}}$ to sequester doxorubicin may be mediated via a complexed copper ion, we treated HM.LNm5 with D-penicillamine or bathocuproine sulfonate (BCS) chelators and assayed anthracycline sensitivity. Consistent with our hypothesis, both agents sensitized the cells to doxorubicin (Figure 5, B and C). Interestingly, epirubicin and doxorubicin bind copper ions at ratios of 2:1 and 1:1, respectively (17) (Figure 5D), thus, it is possible that steric hindrance precludes formation of a complex between $\mathrm{PrP}^{\mathrm{C}}$ and epirubicin, accounting for the preferential binding of $\operatorname{PrP}^{\mathrm{C}}$ to doxorubicin over epirubicin. Together, these data provide a biochemical mechanism for the different affinities of anthracycline binding to $\mathrm{PrP}^{\mathrm{C}}$ based on the formation of copper ion complexes. 
A

O High-affinity $\mathrm{Cu}^{2+}$ and putative Doxorubicin binding.

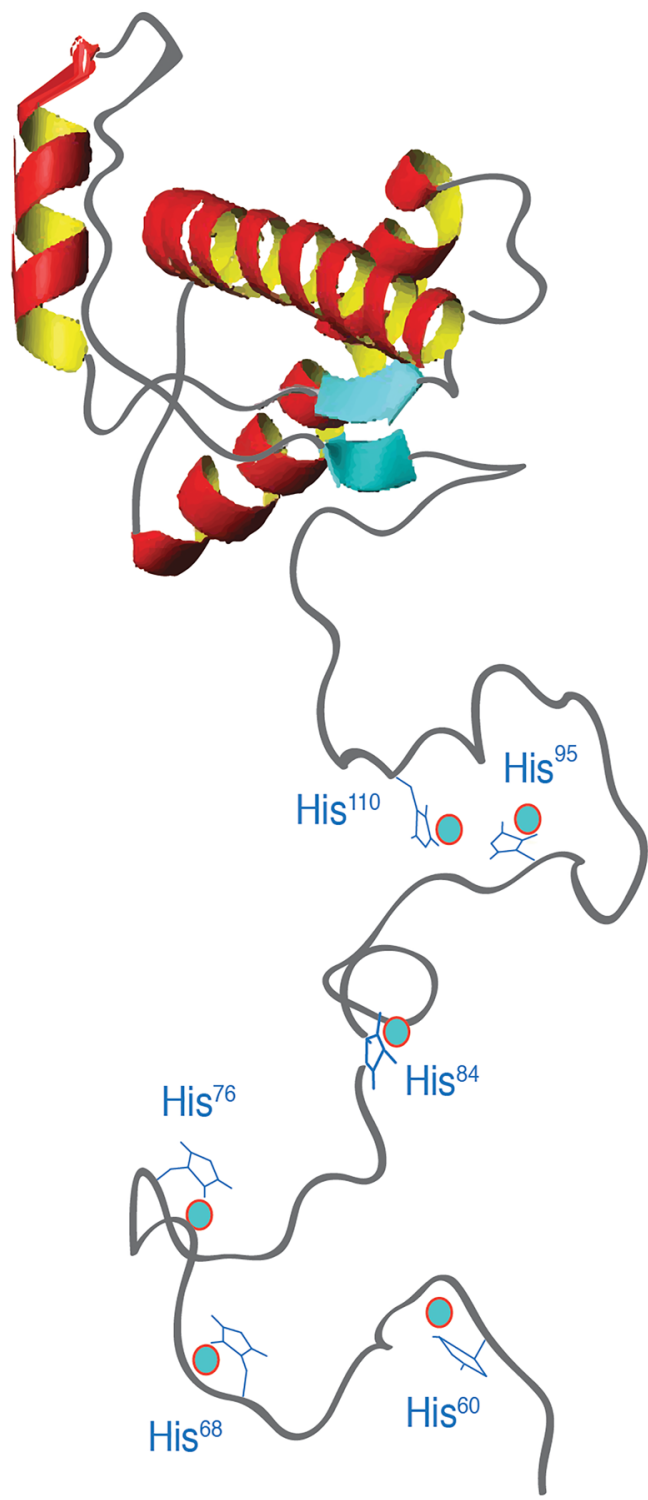

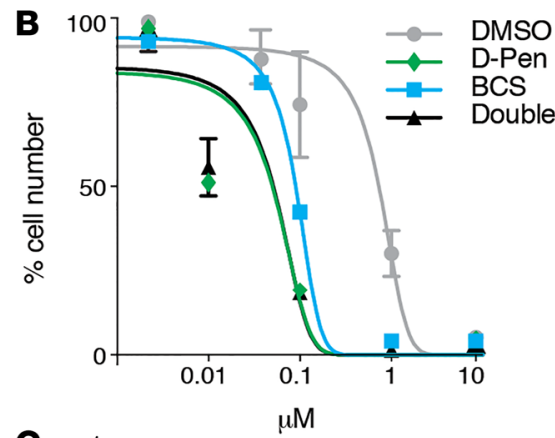

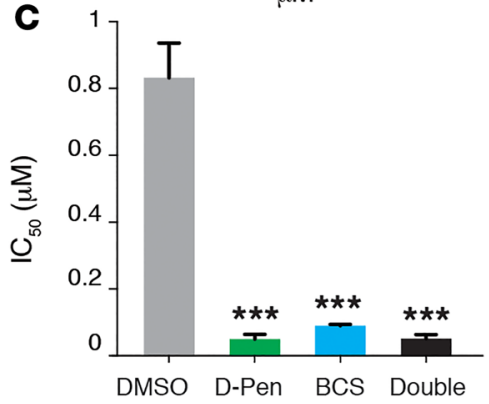

\section{Doxorubicin: $\mathrm{Cu}^{2+}(1: 1)$}

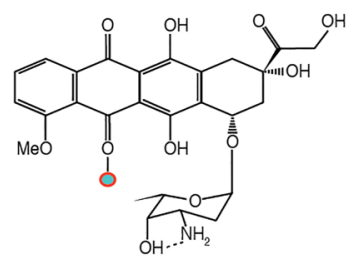

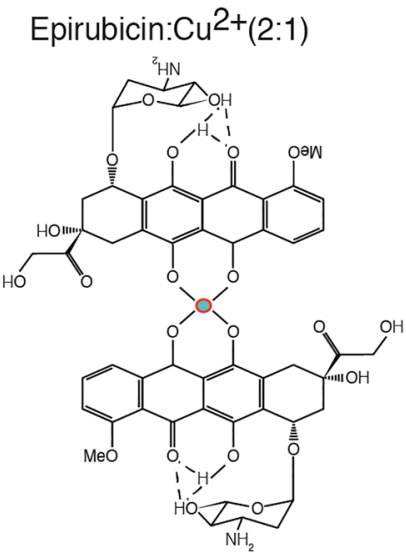

Figure 5. Complexing of doxorubicin and $\mathrm{PrP}^{\mathrm{C}}$ requires free copper ions. (A) The unstructured $\mathrm{N}$-terminal tail of $\mathrm{Pr} \mathrm{PC}^{\mathrm{C}}$ contains 6 histidine residues that bind copper and potentially complex with doxorubicin. (B and $\mathbf{C}$ ) HM.LNm5 cells treated with copper chelators D-penicillamine (D-Pen), bathocuproinedisulfonic acid (BCS), or both are significantly more sensitive to doxorubicin than those treated with vehicle (DMS; ${ }^{* * *} P=0.0011$; error bars represent \pm SEM). $P$ values were determined using 2-tailed Student's $t$ test. Determination of $\mathrm{IC}_{50}$ values of MDA-MB-231 HMLMN5 cells treated with copper chelators. (D) The chelation ratios of doxorubicin and epirubicin with copper are $2: 1$ and $1: 1$, respectively (via C5 and C6 in doxorubicin, $\mathrm{C} 11$ and $\mathrm{C} 12$ in epirubicin).

\section{Discussion}

To date there are limited studies on the inherent functions of $\mathrm{PrP}^{\mathrm{C}}$ that relate to cancer progression and chemoresistance. The posited heterogeneous functions of $\mathrm{PrP}^{\mathrm{C}}$ relate to changes in its processing, including differential folding, glycosylation, cleavage, and metal binding, resulting in the capability to regulate multiple different substrates and cellular processes (11). While $\beta$-cleavage occurs mainly under prion-mediated pathological conditions, $\alpha$-cleavage and secreted full-length protein are part of normal cellular $\mathrm{PrP}^{\mathrm{C}}$ processing. We observed high levels of full-length $\mathrm{PrP}^{\mathrm{C}}$ in both $\mathrm{TNBC}$ cell lines and primary patient samples $(18,19)$. Studies into metastatic gastric cancer found that although $\operatorname{PrP}^{\mathrm{C}}$ was more often highly expressed at secondary sites than the primary, there was no significant increase in $\operatorname{PrP}^{\mathrm{C}}$ expression levels at a metastatic site compared with the primary site in the same gastric cancer patient (20). 


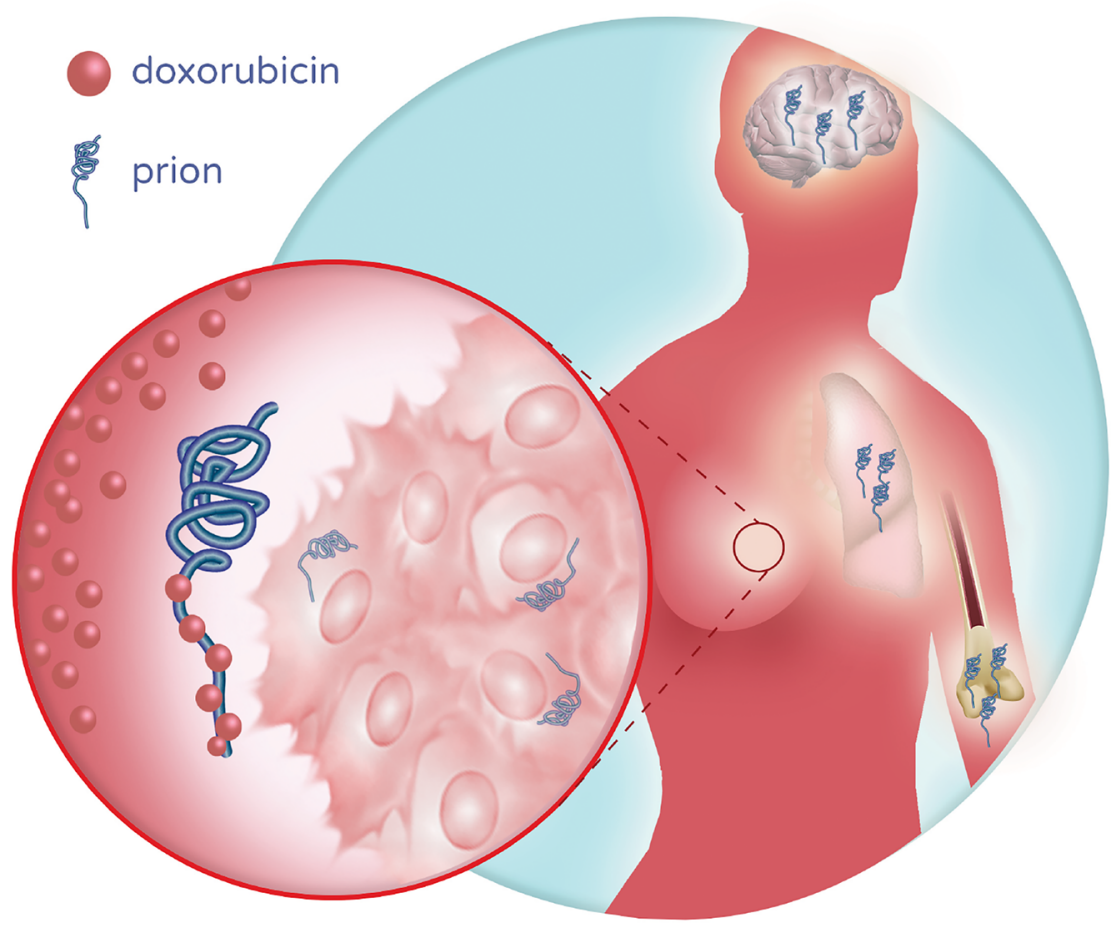

Figure 6. Model for prion protein-mediated resistance to anthracyclines. Schematic illustration of the potential implications of high concentrations of $\mathrm{PrP}^{\mathrm{C}}$, which could sequester anthracyclines in the tumor microenvironment, systemic circulation and/or distant tissues, reducing local bioavailability, and/or modifying pharmacokinetics and pharmacodynamics. Our data suggest that the effect is more pronounced for doxorubicin than epirubicin due to structural determinants of complex copper ion formation.

This suggests that overexpression of $\mathrm{PrP}^{\mathrm{C}}$ is an early determinant of chemoresistant metastasis and may be useful as a prognostic indicator. We suggest that $\operatorname{Pr}^{\mathrm{C}}$ could be a prognostic indicator for metastatic relapse in response to doxorubicin resistance. We observed a robust association between human serum $\mathrm{PrP}^{\mathrm{C}}$ and doxorubicin efficacy in a controlled in vitro setting, suggesting that $\mathrm{PrP}^{\mathrm{C}}$-drug complexes exist in physiologic conditions. This interaction precludes doxorubicin from entering the nuclei of target cells

Table 2. Characteristics of the Brisbane Breast Bank anthracycline chemotherapy cohort

\begin{tabular}{|c|c|c|c|c|}
\hline & \multicolumn{2}{|c|}{ FAC group } & \multicolumn{2}{|c|}{ FEC group } \\
\hline & $n$ & $\%$ & $n$ & $\%$ \\
\hline Node negative & 6 & $28.6 \%$ & 22 & $34.4 \%$ \\
\hline Grade 1 & 1 & $4.8 \%$ & 3 & $4.5 \%$ \\
\hline Grade 2 & 7 & $33.3 \%$ & 30 & $45.5 \%$ \\
\hline Grade 3 & 13 & $61.9 \%$ & 33 & $50.0 \%$ \\
\hline ER negative & 4 & $19.0 \%$ & 10 & $15.2 \%$ \\
\hline ER positive & 17 & $81.0 \%$ & 56 & $84.8 \%$ \\
\hline non-TN & 18 & $85.7 \%$ & 60 & $90.9 \%$ \\
\hline TNBC & 3 & $14.3 \%$ & 6 & $9.1 \%$ \\
\hline Tumor $\operatorname{PrP}^{\mathrm{C}}$ negative & 8 & $38.1 \%$ & 19 & $28.8 \%$ \\
\hline
\end{tabular}


altering bioavailability. Systemic dissemination of serum $\operatorname{PrP}^{\mathrm{C}}$ could create $\mathrm{PrP}^{\mathrm{C}}$-mediated regions of low doxorubicin bioavailability, contributing to privileged chemoresistant sites allowing engraftment of micrometastases (21). We propose that patients that present with high expression levels of cellular or soluble $\operatorname{PrP}^{\mathrm{C}}$ represent a high risk for chemoresistance and require altered management.

We describe the molecular mechanism of doxorubicin resistance via the highly conserved octarepeats being capable of binding multiple copper ions to histidines (22). In support of this, deletion of the 4 amino-terminal octarepeats resulted in a truncated $\operatorname{PrP}^{\mathrm{C}}$ protein, restoring sensitivity to doxorubicin in gastric cancer cells (23). Our results suggest that $\operatorname{PrP}^{\mathrm{C}}$ is able to efficiently complex doxorubicin, as opposed to epirubicin, where access to C5/C6 is restricted by hydrogen bonding from the hydroxyl group on the amino sugar moiety $(15,17,22)$. This interaction is potentially supported by the tumor microenvironment, given that serum copper levels measured in breast cancer patients are twice those of age-matched healthy controls (24). A thorough understanding of $\mathrm{PrP}^{\mathrm{C}}$-anthracycline complex copper ion structures could inform the development of new sensitization strategies.

Collectively, this study shows what we believe to be a novel binding function of $\operatorname{PrP}^{\mathrm{C}}$ that is likely to occur to some degree in systemic circulation and/or the tumor microenvironment, altering the pharmacokinetic and pharmacodynamic profiles of one of the most important classes of chemotherapy used in oncology (Figure 6). The findings indicate that breast cancer patients with high levels of serum or tumor $\mathrm{PrP}^{\mathrm{C}}$ are at higher risk of relapse than $\mathrm{PrP}^{\mathrm{C}}$-negative counterparts; therefore assaying $\mathrm{PrP}^{\mathrm{C}}$ could have a place in the clinical diagnostic setting to help determine the most appropriate chemotherapy regimen. Histological assessment of residual disease at surgery after neoadjuvant therapy is currently accepted as the most accurate predictor of long-term response and yet PRNP RNA level stratified outcomes among patients who did not achieve pCR after neoadjuvant treatment with FAC/T or FEC/T.

Successful TNBC therapy faces challenges involving intra- and intertumoral heterogeneity. Resulting metastatic relapse represents the outcomes of inherent variability of individual patient response to frontline therapy that includes doxorubicin. Our study provides the capability to predict patient response based on therapeutic choices that have major effects on clinical efficacy.

\section{Methods}

Analysis of genomic data sets. Analysis of PRNP expression, methylation, and copy number status was done using publicly available data sets from TCGA and Metabric consortia (8). Relationships between $P R N P$ expression and relapse-free survival were determined by Kaplan-Meier analysis of neoadjuvant trial data sets normalized as part of the KM plotter data set (GEO accession, FAC/T: GSE25065, GSE20194, GSE25055, GSE20271; FEC/T: GSE25065, GSE20194, GSE42822). The statistical tests used are indicated in respective figure legends.

Cell culture. MDA231, MDA436, Hs578t, and BT549 cells were sourced from the ATCC. MDA231 clonal derivatives were provided in-house. Cells were confirmed to be negative for mycoplasma and authenticated by short tandem repeat analysis every 6 months. All lines were maintained in Dulbecco's Modified Eagle Medium with 5\% FBS and antibiotics, except BT549, which was maintained in RPMI with 5\% FBS and antibiotics. For genetic depletion studies, PRNP was transiently silenced with On-Target Plus smartpool (Millennium) or control siRNAs (Invitrogen), using Lipofectamine 2000 (Invitrogen). Samples were analyzed after 48 hours. For glycosylation studies, cells were incubated for 24 hours in the presence of $50 \mathrm{ng} / \mathrm{ml}$ brefeldin A (MilliporeSigma). Exosomes were isolated as described earlier (25).

PNGaseF digest. Cell pellets were lysed in lysis buffer containing protease inhibitors (50 $\mathrm{mM}$ Tris, $\mathrm{pH} 7.4,150 \mathrm{mM} \mathrm{NaCl}, 0.5 \%$ [w/v] sodium deoxycholate, $0.5 \%$ [w/v] Triton X-100) for 30 minutes at $4^{\circ} \mathrm{C}$. Crude lysates were precleared by spinning at $1000 \mathrm{~g}$ for 5 minutes, with the supernatants collected and balanced for total protein after BCA assay following the manufacturer's instructions (Pierce BCA Assay protein kit, Thermo Fisher Scientific). Proteins were denatured by boiling $\left(100^{\circ} \mathrm{C}\right)$ for 5 minutes in a final concentration of $0.5 \%$ SDS and $0.5 \% \beta$-mercaptoethanol and cooled to room temperature briefly. Samples were then treated with peptide-N-glycosidase F (PNGaseF, 500 units, Promega) in incubation buffer ( $50 \mathrm{mM}$ sodium phosphate $\mathrm{pH} 7.5)$ containing NP40 (1\% final concentration) overnight at $37^{\circ} \mathrm{C}$. The conditioned media were methanol precipitated $(1: 5$ parts ice-cold $100 \%$ methanol), denatured, and PNGaseF treated again, as described above. PNGaseF-treated samples were then boiled for 5 minutes in $\times 1$ sample buffer for Western blotting. 
Immunoblotting. Whole cell protein lysates were prepared in ice-cold lysis buffer $(150 \mathrm{mM} \mathrm{NaCl}$, $10 \mathrm{mM}$ Tris-Cl, pH 7.4, 5 mM EDTA, 1\% Triton X-100) supplemented with protease inhibitors (Leupeptin, Pepstatin, PMSF [MilliporeSigma]). Immunoblots were probed with anti-PrP $\mathrm{P}^{\mathrm{C}}$ antibodies (Millipore, 3F4; Santa Cruz, 8B4; Cayman Chemicals, SAF32; Abcam, 8H4) or anti-albumin, -actin, or -tubulin (MilliporeSigma). Membranes were developed using secondary anti-mouse/rabbit antibodies (Thermo Fisher Scientific) and then visualized and quantified relative to loading controls by optical density (ImageJ; NIH).

Immunofluorescence. In short, $5 \times 10^{4}$ cells were seeded onto 18 -mm glass coverslips. Then, 24 hours later, they were washed in PBS, fixed with cold $74 \%$ paraformaldehyde, and permeabilized with $0.1 \%$ Triton X-100 for 15 minutes at room temperature. Cells were blocked with 1\% BSA and incubated with primary antibody (1:50 in 0.1\% BSA in PBS, anti-prion clone 3F4, MAB1562; Merck) overnight at $4^{\circ} \mathrm{C}$ and then secondary antibody (1:500, anti-mouse, Z025902-2; anti-rabbit, M073701-2; Agilent Dako) for 30 minutes at room temperature. Immunostained cells were then washed and mounted with ProLong Gold Antifade Mountant containing DAPI for microscopy. Images were taken on a Zeiss 780-NLO confocal microscope.

IHC. $\operatorname{PrP}^{\mathrm{C}}$ protein expression was assessed in the CTx resource (Brisbane Breast Bank; ref. 26), a cohort comprising tumor samples from 95 breast patients treated with either FAC or FEC regimens, with associated clinicopathologic data, including breast cancer-specific survival. Characteristics of this cohort are described in Tables 1 and 2. Tumor-rich tissue was sampled in duplicate in TMAs, linked to clinicopathologic information through TMA position. Four- $\mu \mathrm{m}$ TMA sections were blocked in Sniper (Biocare Medical) plus 2\% BSA for 15 minutes. Primary $\operatorname{PrP}^{\mathrm{C}}$ antibodies (3F4, MAB1562; Merck, or SAF32, 189720; Cayman Chemical Company) were diluted 1:50 in Da Vinci Green diluent (Biocare Medical), and the Mach1 kit (Biocare Medical) was used for detection. Hematoxylin-counterstained sections were scanned at $\times 40$ magnification and digital images were scored blind by 2 molecular pathologists (JK and JS). The maximum scores of duplicate cores were taken for each case, and associations between the expression of $\mathrm{PrP}^{\mathrm{C}}$ and clinicopathologic variables were investigated using $\chi^{2}$, Fisher's exact, and log-rank tests (GraphPad Prism v7).

Chemotherapy dose-response analysis. Cells were seeded in 24 -well plates $\left(5 \times 10^{4} /\right.$ well $)$ and then incubated for 72 hours in the presence of gefitinib $(0-100 \mu \mathrm{M})$, cisplatin $(0-1 \mathrm{mM})$, docetaxel $(0-10 \mathrm{nM})$, gemcitabine $(0-1 \mu \mathrm{M})$, or doxorubicin $(0-10 \mu \mathrm{M})$. In some experiments, cells were seeded in 96-well format $\left(1 \times 10^{4} /\right.$ well $)$, and FBS was replaced with $10 \%$ human serum. Metabolic rate was assayed as a readout of cell number using the MTS one-step assay.

Immunoprecipitation. Conditioned media from cells treated with doxorubicin, epirubicin, brefeldin $\mathrm{A}$, and/or PRNP siRNA were incubated for 2 hours at room temperature with $1 \mu \mathrm{g}$ anti-PrPC (clones 3F4, MAB1562 or 8B4, Merck; sc-47729, Santa Cruz) or an anti-rabbit IgG control (sc-66931, Santa Cruz). Complexes were washed twice with cold PBS and then incubated with $300 \mu$ Protein G beads (11719416001, Merck) for 2 hours at room temperature. After washing twice with cold PBS, $100 \mu$ of bead mixture was analyzed by spectrophotometry $(480 \mathrm{~nm})$.

ELISA for soluble $\operatorname{Pr}^{C}$. A quantitative ELISA for soluble $\mathrm{PrP}^{\mathrm{C}}$ was performed using the betaPrion HUMAN ELISA kit (847-0104000104, Analytik Jena), according to the manufacturer's instructions. Briefly, serum samples were thawed on ice, and $100 \mu 1$ was incubated in the ELISA plates for 2 hours at room temperature, washed 5 times, and then dried. $100 \mu 1$ anti- $\operatorname{PrP}^{\mathrm{C}}$ Ache tracer was added to each well, covered, and incubated for 2 hours at room temperature. Next, the plates were washed 5 times with wash buffer, and $200 \mu$ Ellman's reagent was added to each well. Plates were incubated in darkness at room temperature for 30 minutes and read at $405 \mathrm{~nm}$ and $414 \mathrm{~nm}$. Absolute $\operatorname{PrP}^{\mathrm{C}}$ levels were validated against a calibration curve of pure full-length recombinant $\operatorname{PrP}^{\mathrm{C}}$ (Prionatis $\operatorname{rec} \operatorname{PrP}$, RPA0101S).

Statistics. Results are presented as mean \pm SEM of replicate analyses and are either representative or inclusive of at least 3 independent experiments. In all figures, significant differences between specified pairs of conditions were assessed using 2-tailed Student's $t$ tests, with $P<0.05$ considered significant. $\mathrm{IC}_{50}$ values were calculated by interpolation of sigmoidal dose-response curves produced from nonlinear regression analyses.

Study approval. The use of patient data and clinical samples in this study was approved by the human research ethics committees of the University of Queensland, QIMR Berghofer Medical Research Institute, and The Royal Brisbane and Women's Hospital. 


\section{Author contributions}

APW, JMS, AM, and SJC designed experiments, coordinated collaborations, and performed data analyses. APW executed most of the experiments. FA analyzed clinical gene expression profiles. CA and MM analyzed prion expression in cell lines. SH carried out immunofluorescence staining and analysis. $\mathrm{RL}$ analyzed conditioned media and isolated exosomes. KF and $\mathrm{CN}$ collected clinical samples and collated patient records (radiology, pathology). AJD performed analysis of soluble prion in patient samples. JMS, JRK, and SRL carried out the staining of breast cancer cohorts, scoring, and analyses. STF and VL performed and analyzed PNGase immunoblotting. CNJ gifted the MDA-MB-231 subclones.

\section{Acknowledgments}

We would like to thank Parmjit Jat, Iryna Benilova, and Simon Mead (UCL Institute of Prion Diseases) for critical review and feedback on this manuscript. We thank Jason Lee, QIMR Berghofer Medical Research Institute, for his help with data analysis, revision, and formatting. We also acknowledge the Brisbane Breast Bank for clinical samples for IHC and ELISA studies. This study makes use of data generated by the Molecular Taxonomy of Breast Cancer International Consortium (Metabric). This study was supported by funding from Australian National Health \& Medical Research Council project grants (APP1068510 to AM and APP1113867 and APP1017028 to SRL) and the Practitioner Fellowship (APP1105784 to SJC).

Address correspondence to: Andreas Möller, QIMR Berghofer Medical Research Institute, Locked bag 2000, Royal Brisbane Hospital, Herston, Queensland 4029, Australia. Phone: 61.7.33620339; Email: andreas.moller@qimrberghofer.edu.au.

1. Turner N, Biganzoli L, Di Leo A. Continued value of adjuvant anthracyclines as treatment for early breast cancer. Lancet Oncol. 2015;16(7):e362-e369.

2. Glück S. Adjuvant chemotherapy for early breast cancer: optimal use of epirubicin. Oncologist. 2005;10(10):780-791

3. Liedtke C, et al. Response to neoadjuvant therapy and long-term survival in patients with triple-negative breast cancer. $J$ Clin Oncol. 2008;26(8):1275-1281.

4. Lewis V, Johanssen VA, Crouch PJ, Klug GM, Hooper NM, Collins SJ. Prion protein "gamma-cleavage": characterizing a novel endoproteolytic processing event. Cell Mol Life Sci. 2016;73(3):667-683.

5. Déry MA, et al. Endoplasmic reticulum stress induces PRNP prion protein gene expression in breast cancer. Breast Cancer Res. 2013;15(2):R22.

6. Antony H, Wiegmans AP, Wei MQ, Chernoff YO, Khanna KK, Munn AL. Potential roles for prions and protein-only inheritance in cancer. Cancer Metastasis Rev. 2012;31(1-2):1-19.

7. Meslin F, et al. Efficacy of adjuvant chemotherapy according to Prion protein expression in patients with estrogen receptor-negative breast cancer. Ann Oncol. 2007;18(11):1793-1798.

8. Curtis C, et al. The genomic and transcriptomic architecture of 2,000 breast tumours reveals novel subgroups. Nature. 2012;486(7403):346-352.

9. Johnstone $\mathrm{CN}$, et al. Functional and genomic characterisation of a xenograft model system for the study of metastasis in triple-negative breast cancer. Dis Model Mech. 2018;11(5):dmm032250.

10. Fevrier B, et al. Cells release prions in association with exosomes. Proc Natl Acad Sci USA. 2004;101(26):9683-9688.

11. Brim S, Groschup MH, Kuczius T. Copper and zinc interactions with cellular prion proteins change solubility of full-length glycosylated isoforms and induce the occurrence of heterogeneous phenotypes. PLoS ONE. 2016;11(4):e0153931.

12. Corato M, et al. Doxorubicin and congo red effectiveness on prion infectivity in golden Syrian hamster. Anticancer Res. 2009;29(7):2507-2512.

13. Pham N, Akonasu H, Shishkin R, Taghibiglou C. Plasma soluble prion protein, a potential biomarker for sport-related concussions: a pilot study. PLoS ONE. 2015;10(2):e0117286.

14. Twelves CJ, Dobbs NA, Aldhous M, Harper PG, Rubens RD, Richards MA. Comparative pharmacokinetics of doxorubicin given by three different schedules with equal dose intensity in patients with breast cancer. Cancer Chemother Pharmacol. 1991;28(4):302-307.

15. Jabłońska-Trypuć A, Świderski G, Krętowski R, Lewandowski W. Newly synthesized doxorubicin complexes with selected metals-synthesis, structure and anti-breast cancer activity. Molecules. 2017;22(7):1106.

16. Millhauser GL. Copper binding in the prion protein. Acc Chem Res. 2004;37(2):79-85.

17. Malatesta V, Morazzoni F, Gervasini A, Arcamone F. Chelation of copper(II) ions by doxorubicin and 4'-epidoxorubicin: an e.s.r. study. Anticancer Drug Des. 1985;1(1):53-57.

18. Taylor DR, et al. Role of ADAMs in the ectodomain shedding and conformational conversion of the prion protein. $J$ Biol Chem. 2009;284(34):22590-22600.

19. Walmsley AR, Watt NT, Taylor DR, Perera WS, Hooper NM. alpha-cleavage of the prion protein occurs in a late compartment of the secretory pathway and is independent of lipid rafts. Mol Cell Neurosci. 2009;40(2):242-248.

20. Atkinson CJ, Zhang K, Munn AL, Wiegmans A, Wei MQ. Prion protein scrapie and the normal cellular prion protein. Prion. 2016;10(1):63-82. 
21. Sceneay J, Smyth MJ, Möller A. The pre-metastatic niche: finding common ground. Cancer Metastasis Rev. 2013;32(3-4):449-464.

22. Viles JH, Cohen FE, Prusiner SB, Goodin DB, Wright PE, Dyson HJ. Copper binding to the prion protein: structural implications of four identical cooperative binding sites. Proc Natl Acad Sci USA. 1999;96(5):2042-2047.

23. Wang JH, et al. Octarepeat peptides of prion are essential for multidrug resistance in gastric cancer cells. J Dig Dis. 2012;13(3):143-152

24. Pavithra V, Sathisha TG, Kasturi K, Mallika DS, Amos SJ, Ragunatha S. Serum levels of metal ions in female patients with breast cancer. J Clin Diagn Res. 2015;9(1):BC25-Bc27.

25. Lötvall J, et al. The launch of Journal of Extracellular Vesicles (JEV), the official journal of the International Society for Extracellular Vesicles - about microvesicles, exosomes, ectosomes and other extracellular vesicles. J Extracell Vesicles. 2012;1.

26. McCart Reed AE, Saunus JM, Ferguson K, Niland C, Simpson PT, and Lakhani SR. The Brisbane Breast Bank. Open Journal of Bioresources Web site. https://openbioresources.metajnl.com/articles/10.5334/ojb.33/. Accessed February 18, 2019. 